\title{
Ovários anômalos em \\ Passalus convexus Dalman, 1817 (Coleoptera: Passalidae)
}

\author{
Claudio R. V. Fonseca (*)
}

\begin{abstract}
Resumo
O número de ovaríolos parece ser um importante subsídio para a compreensão de questōes relativas à evolução e ao comportamento dos insetos. Em Passalidae, o número de $2-2$ ovaríolos tem se mostrado constante para toda familia. Anomalias năo freqüentes foram encontradas e aqui registradas, em dois exemplares de Passalus convexus Dalm., que apresentaram 2-3 e $2-4$ ovariolos.
\end{abstract}

\section{INTRODUÇÃo}

O estudo do número de ovaríolos tem sugerido existir uma estreita relação entre a quantidade de ovariolos e hábitos de oviposição, comportamento de nidificação (Halffter \& Martínez, 1980), estratégia de reprodução, além de contribuir para melhor compreensão dos problemas relativos à evolução, indicando as$\operatorname{sim}$ as relações entre as várias famílias de uma dada ordem. como acontece no caso específico de Coleoptera.

Segundo Balduf (1964), estudos do número de ovaríolos poderão fornecer dados que facilitarão a classificação de grupos supraespecíficos, assim como ajudarão a traçar o desenvolvimento evolutivo de uma ordem.

Uma grande variação no número de ovaríolos tem sido verificada em Coleoptera. Estudos têm sugerido q:ıe 6-6 ovaríolos é o número básico para Scarabaeoidea (Ritcher, 1974), no entanto, 2-2 ovaríolos são encontrados ainda em Curculionidae e Scolytidae (Robertson, 1961).

Para Passalidae, 31 espécies já foram investigades até agora. Williams (1945), estudando a anatomia interna da genitália de Coleoptera, dissecou exemplares de Popilius disjunctus e afirmou ter encontrado um par de ovaríolos para cada oviduto lateral, ou seja, o número de 2-2 ovaríolos.
Krause (1946) verificou o mesmo resultado observando Popilius disjunctus. Robertson (1961), ratifica em seu trabalho o número de 2-2 ovaríolos encontrados em três indivíduos da mesma espécie.

Baker (1973), reportou Pentalobus palini (Percheron, 1844), Pentalobus barbatus (Fab., 1801) e Pentalobus savagei (Percheron, 1844), apresentavam o número de 2-2 ovaríolos.

Reyes-Castilio e Ritcher (1973), encontraram a mesma condição de 2-2 ovaríolos em Aulacocyclus edientulus (MacLeay), Vindex agnoscendus (Percheron), Helisus tropicus (Percheron), Heliscus descipiens Kuwert, Odontotaenius disiunctus (Illiger), Odontota€nius striatopuntatus (Percheron), Verres hageni Kaup, Paxillus ieachi MacLeay, Passalus (Pertinax) punctatostriatus (Percheron), Passalus (Pertinax) caelatus Erichson, Passalus (Passalus) punctiger St. Far. e Serv, e Ptichopus angulatus (Percheron).

Ritcher (1974), em seu trabalho sobre ovariolos em Scarabaeoidea, achou resultado semeihante aos demais autores, para as espécies Aulacocyclus errans (Blackl.), Cylindricaulus patalis (Lewis), Verres furcilabris (Esch.) e Episphenoides australasicus Perch. (sic) .

No presente trabalho, são examinadas 11 espécies de Passalidae da bacia amazônica, para tentar reconfirmar a uniformidade da família para esta região.

\section{MATERIAIS E MÉTODOS}

Os Passalidae foram capturados em troncos caídos na periferia de mata primária, localizada no $\mathrm{Km} 18$ da rodovia BR-174, ManausCaracarai, no Estado do Amazonas, Brasil.

\footnotetext{
(*) - Instituto Nacional de Pesquisas da Amazônia, Manaus.
} 
Os troncos foram explorados com auxílio de machadinhas e facões, manejados com cautela, para não danificar o contorno das galerias e nem mutilar as larvas, ovos e adultos ali abrigados.

Todo material encontrado era acondicionado ein vidros que, depois de rotulados, eram encaminhados ac laboratório para exame das gônadas.

As dissecções eram efetuadas usando-se uma tesoura de ponta fina, com a qual davamse duas incisões laterais no abdome. Um corte no sentido transversal era dado, para que se pudesse retirar completamente os esternitos abdominais. Em seguida, o ovário era retirado com auxílio de uma pinça de ponta fina A contagem dos ovaríolos era realizada usandose uma lupa estereoscópica. Os exemplares examinados, foram posteriormente montados $\mathrm{e}$ depositados na coleção entomológica do Instituto Nacional de Pesquisas da Amazônia.

\section{Resultados}

O número de 2-2 ovaríolos parece ser uma condição invariável para toda família Passalidae, visto não termos encontrado citações documentando variações. Entretanto, numa série de 400 indivíduos pertencentes aos gêneros Verres, Veturius e Passalus, foram detectadas

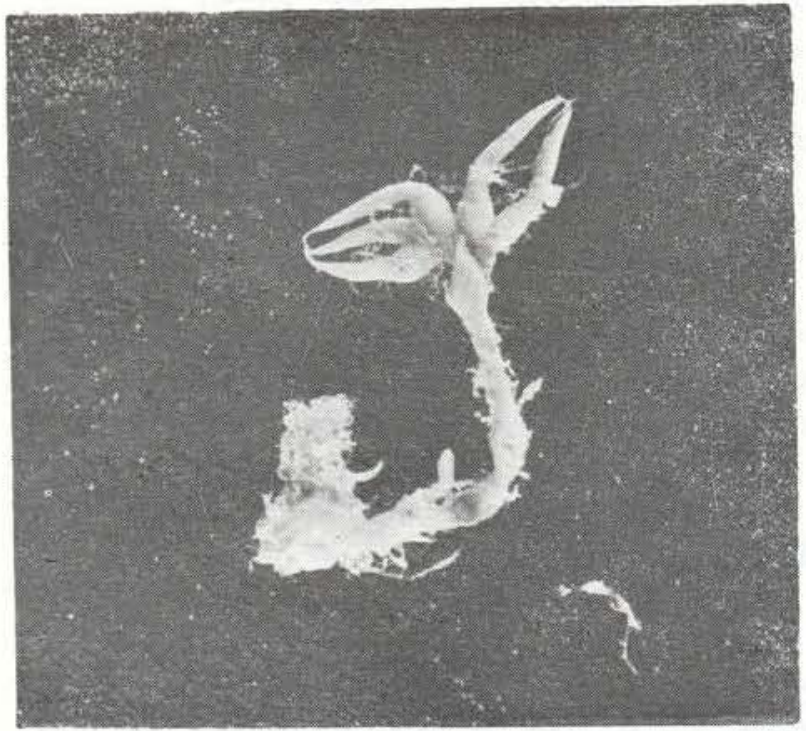

Fig. 1 - Ovário de P. convexus Dalm., com 2-3 ovaríolos. (Aumento $4 \mathrm{x}$ ).

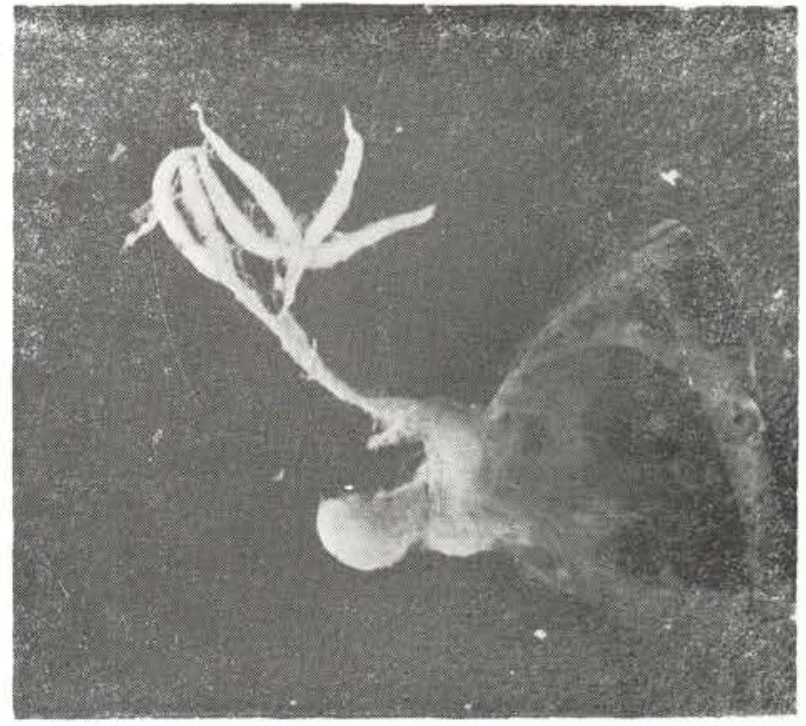

Fig. 2 - Ovário de P. convexus Dalm., com 2--4 ovariolos. (Aumento $4 x$ ).

anomalias em duas fêmeas de Passalus convexus Dalm., dentre 129 fêmeas e 116 machos examinados desta espécie. Os ovários daqueles dois exemplares apresentavam 2-3 e 2-4 ovaríolos (Fig. 1 e 2), fugindo assim ao número usual encontrado nas espécies já estudadas. É interessante notar o fato de que mesmo anômalo, o ovário que possuia 2-3 ovaríolos não demonstrava indícios de inviabilidade; ao contrário, foi possivel detectar folículos em crescimento, enquanto o que apresentava $2-4$ ovaríolos, não mostrava sintomas de atividade de amadurecimento de oócitos.

TABELA I - Número de ovaríolos nos Passalidae estudados

\section{Espécie}

N: de ovariolos

Passalus rhodocanthopoides (Kuwert) 2-2

Passalus convexus Dalman 2-2*

Passalus morio Percheron 2-2

Passalus interruptus (Lin.) 2-2

Passalus glaberrimus Eschscholtz 2-2

Passalus coordinatus (Kuwert) 2-2

Passalus variiphyllus (Kuwert) 2-2

Passalus elfriedae Luederwaldt 2-2

Veturius paraensis Luederwaldt $2-2$

Veturius platyrhinus (Hope) $2-2$

Verres furcilabris (Eschscholtz) 2-2

(*) - Mais que $98 \%$ das fêmeas. 
Considerando que este fenômeno se apresentou numa proporção muito baixa, é possivel que estejamos diante de anomalias não freqüentes, mormente porque não há registro na literatura de outra ocorrência semelhante a esta.

Foram examinadas 11 espécies dos gêneros já referidos e em todas foi constante o número de 2-2 ovaríolos (Tab. I). Este número constante confirma uma bem marcada uniformidade em toda família Passalidae, o que pode constituir uma relação com o hábito de colonizar troncos em decomposição.

\section{AgradecIMENTos}

Agradecemos ao Dr. Paulo F. Buhrnheim pelas sugestōes que apresentou para este trabalho, assim como pelas determinações do material estudado; ao Sr. Elias Bindá pelo apoio dado nos trabalhos de campo.

\section{SUMMARY}

The ovariole number seems to be an important factor in the understanding of evolutionary and behavioral problems. In Passalidae, 2-2 ovarioles appear to be invariable for whole family. Anomalies were rarely found, but included two specimens of Passalus convexus Dalman, which had 2-3 and 2-4 ovarioles respectively.

\section{REFERENCIAS BIBLIOGRAFICAS}

BAKER, W.J.

1973 - The genitalia of three species of Pentalobus (COLEOPTERA:PASSALIDAE). J. Nat. Hist., 47: 435-440.

BALDUF, W.V.

1964 - Numbers of Ovarioles in Heteroptera (INSECTA). Proc. Entomol. Soc. Wash., 66 (1): $2-5$.

HALFFTER, G. \& MARTINEZ, I.

1980 - Etructura y función ovárica en Ecarabaeinae (COLEOPTERA:SCARABAEIDAE). Folia Ent. mexicana, 43: 13-14

KRAUSE, J.B.

1946 - The Structure of gonads of the wood eating beetle, Passalus cornutus Fabricius. Ann. Entomol, Soc. Am., 39: 193-206.

REYES-CASTILLO, P. \& RITCHER, P.O.

1973 - Ovariole Number in Passalidae (COLEOPTERA). Proc. Entomol. Soc. Wash., 75 (4): 478-479.

RITCHER, P.O.

1974 - Ovariole Numbers in Scarabaeoidea (COLEOPTERA:LUCANIDAE, PASSALIDAE, SCA RABAEIDAE). Proc. Entomol. Soc. Wash., 76 (4): $480-494$.

ROBERTSON, J.G.

1961 - Ovariole numbers in Coleoptera. Canad. J. Zool., 39: 245-263.

WILLIAMS, J.L.

1945 - The Anatomy of the Internal Genitalia of some Coleoptera. Proc. Entomol. Soc. Wash., 47 (4): 73-91.

(Aceito para publicaçāo em $26 / 11 / 80$ ) 